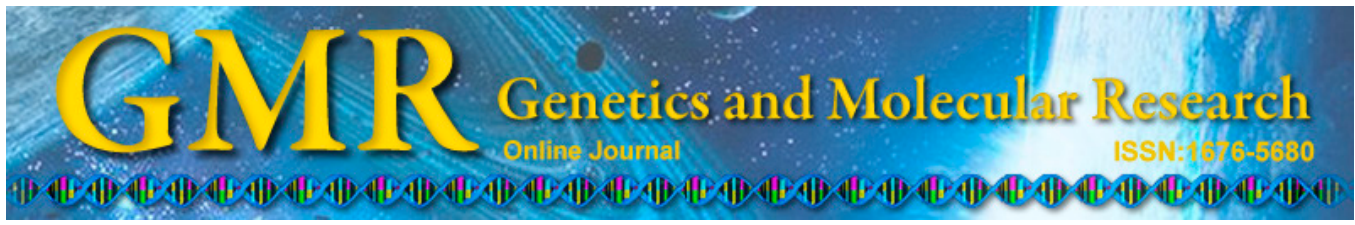

\title{
Brief Note \\ Staging of type 2 diabetes mellitus
}

\author{
S.L. Wu \\ Department of Cardiology, Renmin Hospital of Wuhan University, Wuhan, \\ China \\ Corresponding author: S.L. Wu \\ E-mail: wusonglin222@163.com
}

Genet. Mol. Res. 14 (1): 2118-2121 (2015)

Received May 19, 2014

Accepted October 27, 2014

Published March 20, 2015

DOI http://dx.doi.org/10.4238/2015.March.20.22

\begin{abstract}
There is currently no reported staging system for type 2 diabetes mellitus. Here, I attempted to stage type 2 diabetes mellitus in order to help clinicians, patients, and other interested individuals to effectively evaluate patient conditions.
\end{abstract}

Key words: Type 2 diabetes mellitus; Stage of disease

There is currently no reported staging system for type 2 diabetes mellitus. Here, I attempted to stage type 2 diabetes mellitus to help clinicians, patients, and other interested individuals to effectively evaluate patient conditions. Staging may be helpful in the management of diabetes and could favorably affect health outcomes of patients with diabetes. However, the staging of type 2 diabetes requires revision, and long-term outcome studies are necessary to validate the criteria.

Type 2 diabetes can be classified into five clinical stages:

Stage 1: Pre-diabetes. This group includes patients in the following conditions: a fasting plasma glucose (FPG) level of 100-125 mg/dL (5.6-6.9 mM) (impaired fasting glucose), 2-h plasma glucose (PG) level on oral glucose tolerance test (OGTT) $140-199 \mathrm{mg} / \mathrm{dL}$ (7.8-11.0 $\mathrm{mM}$ ) (impaired glucose tolerance), a hemoglobin A1c (HbA1c) level of 5.7-6.4\% (Genuth et al., 2003; Sacks et al., 2011). In the stage, we are irrespective of comorbidities such as hypertension, dyslipidemia, or overweight. 
Stage 2: Diabetes with no complications. This group includes patients with a FPG level of $\geq 126 \mathrm{mg} / \mathrm{dL}$ (7.0 mM), 2-h PG level on OGTT of $\geq 200 \mathrm{mg} / \mathrm{dL}$ (11.1 mM), HbA1C level of $\geq 6.5 \%$, classic symptoms of hyperglycemia, or a random PG level of $\geq 200 \mathrm{mg} / \mathrm{dL}$ $(11.1 \mathrm{mM})$ (Reaven, 1988; Expert Committee on the Diagnosis and Classification of Diabetes Mellitus, 1997; Genuth et al., 2003; American Diabetes Association, 2010). These patients may or may not have insulin resistance or classic symptoms of hyperglycemia.

Signs of insulin resistance or conditions associated with insulin resistance include acanthosis nigricans, hypertension, dyslipidemia, polycystic ovary syndrome, or small for gestational age birth weight (Genuth et al., 2003).

Stage 3: Diabetes with mild complications. This group includes patients with mild complications, including microalbuminuria and mild diabetic retinopathy (such as microaneurysms, mild hemorrhages) (Ciulla et al., 2003; Levey et al., 2003). Patients may or may not have hyperglycemia or higher or normal levels of fasting and 2-h plasma insulin or proinsulin or C-peptide on OGTT (Chiasson et al., 2002; Nathan et al., 2007).

Stage 4: Diabetes with absolute insulin deficiency. This group includes patients with hyperglycemia, and absolute insulin deficiency which is based on clinical and/or laboratory evidence. Patients may have mild to moderate complications [such as diabetic nephropathy without kidney failure or diabetic retinopathy without proliferative diabetic retinopathy (PDR)] (Ciulla et al., 2003; Fong et al., 2004; KDOQI, 2007).

Laboratory evidence includes levels of fasting plasm insulin or proinsulin or C-peptide lower than the normal lower limit on laboratory's measurement method, or levels of 2-h plasma insulin or proinsulin or C-peptide during OGTT $<5$ times of patient's levels of fasting plasma insulin or proinsulin or C-peptide. In addition, the ratio of fasting glucose to insulin or proinsulin or C-peptide, or of 2-h PG to insulin or proinsulin or C-peptide on OGTT (Sacks et al., 2011) may be considered.

Clinical evidence: In order to achieve desired glycemic goals, the optimal treatment is insulin therapy.

Stage 5: Diabetes with serious complications. This group includes patients with serious complications including hyperglycemic crises, as well as microvascular and macrovascular complications. Patients may have hyperglycemia, as well as higher or lower or normal levels of fasting plasma insulin or proinsulin or C-peptide.

Diabetic ketoacidosis (DKA) and hyperosmolar hyperglycemic state (HHS) are the two most serious acute metabolic complications in diabetes. The diagnostic criteria for DKA include plasma glucose level of $>250 \mathrm{mg} / \mathrm{dL}$, arterial $\mathrm{pH}$ of $<7.30$, serum bicarbonate level of $<18 \mathrm{mEq} / \mathrm{L}$, and positivity for urine ketone and serum ketone. The diagnostic criteria for HHS include plasma glucose level of $>600 \mathrm{mg} / \mathrm{dL}$, arterial $\mathrm{pH}$ of $>7.30$, serum bicarbonate level of $>18 \mathrm{mEq} / \mathrm{L}$, effective serum osmolality of $>320 \mathrm{mOsm} / \mathrm{kg}$, and stupor/coma (Kim, 2007; Kitabchi et al., 2009).

Microvascular complications include retinopathy (neovascularization and vitreous or preretinal hemorrhage), nephropathy, neuropathy (sensory, including history of foot lesions, and autonomic, including sexual dysfunction and gastroparesis), and cardiomyopathy, and macrovascular complications include coronary heart disease, cerebrovascular disease, proliferative diabetic retinopathy, peripheral arterial disease, amputation, and foot ulceration (Genuth et al., 2003; Sacks et al., 2011).

A summary of the staging for type 2 diabetes is shown in Table 1 . 

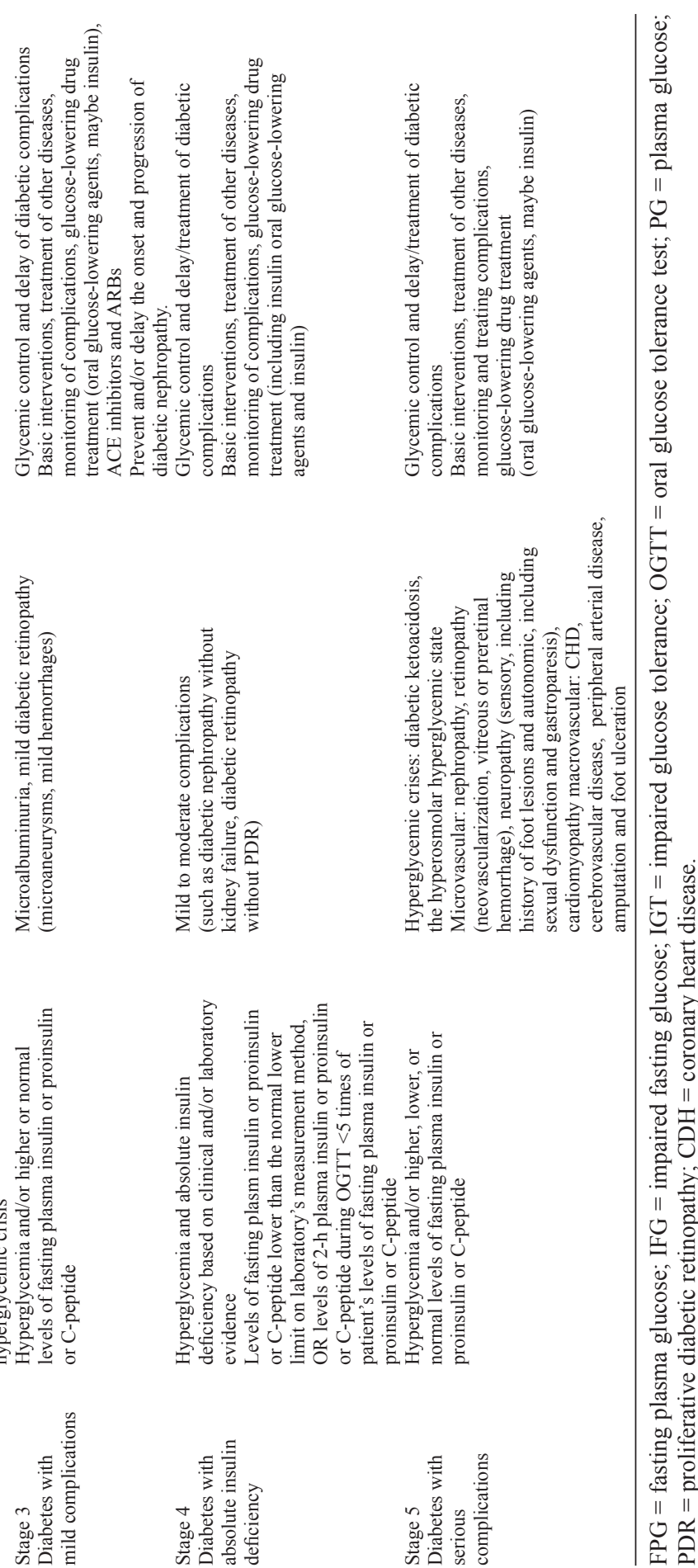


\section{REFERENCES}

American Diabetes Association (2010). Standards of Medical Care in Diabetes-2010: Diabetes Care 33: S11-S61.

Ciulla TA, Amador AG and Zinman B (2003). Diabetic retinopathy and diabetic macular edema: pathophysiology, screening, and novel therapies. Diabetes Care 26: 2653-2664.

Chiasson JL, Josse RG, Gomis R, Hanefeld M, et al. (2002). Acarbose for prevention of type 2 diabetes mellitus: the STOP-NIDDM randomised trial. Lancet 359: 2072-2077.

Expert Committee on the Diagnosis and Classification of Diabetes Mellitus (1997). Report of the Expert Committee on the Diagnosis and Classification of Diabetes Mellitus. Diabetes Care 20: 1183-1197.

Fong DS, Aiello L, Gardner TW, King GL et al. (2004). Retinopathy in diabetes. Diabetes Care 27: S84-S87.

Genuth S, Alberti KG, Bennett P, Buse J, et al. (2003). Follow-up report on the diagnosis of diabetes mellitus. Diabetes Care 26: 3160-3167.

KDOQI (2007). KDOQI clinical practice guidelines and clinical practice recommendations for diabetes and chronic kidney disease. Am J. Kidney Dis. 49: S12-154.

Kim S (2007). Burden of hospitalizations primarily due to uncontrolled diabetes: implications of inadequate primary health care in the United States. Diabetes Care 30: 1281-1282.

Kitabchi AE, Umpierrez GE, Miles JM and Fisher JN (2009). Hyperglycemic crises in adult patients with diabetes. Diabetes Care 32: 1335-1343.

Levey AS, Coresh J, Balk E, Kausz AT, et al. (2003). Practice guidelines for chronic kidney disease: evaluation, classification, and stratification. Ann. Intern. Med. 139: 137-147.

Nathan DM, Davidson MB, DeFronzo RA, Heine RJ, et al. (2007). American Diabetes Association. Impaired fasting glucose and impaired glucose tolerance: implications for care. Diabetes Care 30: 753-759.

Reaven GM (1988). Banting Lecture 1988. Role of insulin resistance in human disease. Diabetes 37: 1595-1607.

Sacks DB, Arnold M, Bakris GL, Bruns DE, et al. (2011). Guidelines and recommendations for laboratory analysis in the diagnosis and management of diabetes mellitus. Clin. Chem. 57: e1-e47. 